\title{
Does levodopa alter depression and psychopathology in Parkinsonism patients? ${ }^{1}$
}

\author{
GAYLE G. MARSH AND CHARLES H. MARKHAM \\ From the Departments of Psychiatry and Neurology, UCLA Centre for the Health Sciences, \\ The Neuropsychiatric Institute, Los Angeles, California, U.S.A.
}

SUMmARY Twenty-seven Parkinsonism patients and 31 controls, matched for age and verbal IQ, were tested on an objectively scored personality test (Minnesota Multiphasic Personality Inventory) at the beginning of the patients' levodopa therapy and three months later. Patients, but not the controls, were retested after 15 months of levodopa treatment. The patients, all of whom were intact intellectually, obtained MMPI scores indicating moderate depression before beginning levodopa treatment. There was no test evidence to indicate that levodopa significantly increased or decreased the amount of depression in the patients after three or 15 months of levodopa. The patient group, however, significantly increased their Index of Psychopathology (Ip) score after 15 months of levodopa but not after three months.

Mild to severe emotional symptoms are not unusual in patients with Parkinson's disease (Patrick and Levy, 1922; Jackson et al., 1923; Mjönes, 1949; Warburton, 1967; Mindham, 1970). Jackson and his associates (1923) graphically described the emergence of severe emotional disorders in Parkinsonism patients who were often found to experience emotional symptoms before motor symptoms by months or years. In 1958, Schwab and England included psychological disorders as part of the symptomatology of Parkinson's disease-for example, changes in personality, depression, agitated states, excessive anxiety, mental disorganisation and impairment, confusion, dementia, and psychotic symptoms, such as pathological suspiciousness, hallucinations, and delusions.

Transitory emotional disturbances similar to those symptoms described above have been observed in patients with Parkinson's disease during levodopa treatment. These disturbances range from agitation, restlessness, and depression to suicide attempts and overt psychosis with hallucinatory activity (Yahr et al., 1968; Barbeau, 1969; Calne et al., 1969; Cotzias et al., 1969; Klawans and Garvin, 1969; Cherington,

1 Studies performed in the Department of Neurology with partial support from the Lawrence Harvey Fund.
1970; Jenkins and Groh, 1970a, b; McDowell et al., 1970; Mawdsley, 1970; Treciokas et al., 1970; Damasio et al., 1971). In most cases, lowering the levodopa dosage eliminated the adverse emotional reactions. However, in a few cases, levodopa had to be discontinued before the emotional side-effects subsided. Sacks et al. (1970) found demented patients with Parkinson's disease to be severely affected emotionally by levodopa. Damasio et al. (1971) report that 13 of their 15 patients who developed or increased their psychiatric symptoms had a previous psychiatric history. Chronic schizophrenic patients after being placed on levodopa for druginduced Parkinsonism deteriorated further in their mental status (Tobias and Merlis, 1970).

In addition to the observations describing adverse emotional side-effects due to levodopa, Barbeau (1969) and Yahr et al. (1969) also observed an alleviation of depression in many patients who had been apathetic and depressed before levodopa treatment. Wagshul and Daroff (1970) found depressive reactions in only two of 125 patients treated with levodopa, one of whom had a history of previous depressive episodes. Because not all patients with Parkinson's disease experience distressing emotional side-effects from levodopa, it is conceivable that the reported 
clinical observations of emotional abnormalities during levodopa treatment relate to exacerbations of pre-existing emotional malfunctioning such as Barbeau (1969) and Tobias and Merlis (1970) have suggested rather than to the emergence of a new emotional disorder.

In all the studies mentioned above, emotional functioning of the patients has been evaluated at the time of the studies by clinical assessment or by retrospective study of medical records. Both methods are subjective in nature and may inadvertently reflect an interviewer's bias.

The present study, which is part of a larger study (Marsh et al., 1971), was undertaken to investigate the short-term and long-term effects of levodopa on the emotional functioning of Parkinsonism patients with attention being given to the assessment of depression and psychotic ideation in the patients. Because of the subjective nature of the clinical observations which often contain observer bias, a personality test with objective test scores was selected to replace the commonly used clinical judgments as measures of the various facets of emotional functioning. The
TABLE 1

DESCRIPTIVE CHARACTERISTICS OF THE PARKINSONISM PATIENTS AND CONTROL SUBJECTS

\begin{tabular}{|c|c|c|c|c|c|c|}
\hline & \multicolumn{3}{|c|}{$\begin{array}{l}\text { Parkinsonism patients } \\
(22 \text { males; } 5 \text { females })\end{array}$} & \multicolumn{3}{|c|}{$\begin{array}{c}\text { Control subjects }) \\
\text { (13 males; } 18 \text { females })\end{array}$} \\
\hline & Range & Mean & $S D$ & Range & Mean & $S D$ \\
\hline $\begin{array}{l}\text { Age (yr) } \\
\text { Verbal IQ* } \\
\text { Educ. level }\end{array}$ & $\begin{array}{l}44-71 \\
91-138\end{array}$ & $\begin{array}{r}58 \cdot 11 \\
111 \cdot 11\end{array}$ & $\begin{array}{r}6 \cdot 65 \\
11 \cdot 92\end{array}$ & $\begin{array}{l}42-71 \\
92-137\end{array}$ & $\begin{array}{r}57 \cdot 00 \\
113 \cdot 58\end{array}$ & $\begin{array}{r}8 \cdot 75 \\
10 \cdot 68\end{array}$ \\
\hline $\begin{array}{l}\text { (yr) } \\
\text { L-dopa med. } \\
\text { (mth) (g) }\end{array}$ & $8-23$ & $14 \cdot 37$ & 3.96 & $6-18$ & $12 \cdot 35$ & $2 \cdot 60$ \\
\hline $\begin{array}{r}3 \\
15\end{array}$ & $\begin{array}{l}2-9 \\
2-7\end{array}$ & $\begin{array}{l}4 \cdot 44 \\
4 \cdot 14\end{array}$ & $\begin{array}{l}1 \cdot 55 \\
1 \cdot 30\end{array}$ & & & \\
\hline
\end{tabular}

* Satz and Mogel abbreviated WAIS (1962).

test was administered to the patients before levodopa therapy. All patients were retested twice, after approximately three months of levodopa therapy and again after 15 months. A group of control subjects was included in the study. The purpose of this control group was to determine whether any changes in test scores of occurred as a function of repeated administratio $\mathrm{B}$ 을 of the test over time.

TABLE 2

ANTIPARKINSONISM MEDICATION BEING TAKEN

\begin{tabular}{|c|c|c|c|}
\hline Patient & $\underset{\text { pre-test }}{\text { Daily }}$ medication $(\mathrm{mg})$ & $\begin{array}{c}\text { Daily medication }(\mathrm{mg}) \\
(3 \mathrm{mth})\end{array}$ & $\underset{(15 \mathrm{mth})}{\text { Daily }}$ \\
\hline $\begin{array}{r}1 \\
2 \\
3 \\
4 \\
5 \\
6 \\
7 \\
8 \\
9 \\
10 \\
11 \\
12 \\
13 \\
14 \\
15 \\
16 \\
17 \\
18 \\
19 \\
20 \\
21 \\
22 \\
23 \\
24 \\
25 \\
26 \\
27\end{array}$ & $\begin{array}{l}\text { None } \\
\text { Procyclidine 20 } \\
\text { Trihexyphenidyl 4 } \\
\text { Benztropine 3 } \\
\text { Amantadine 300 } \\
\text { None } \\
\text { Benztropine 1 } \\
\text { Benztropine 4 } \\
\text { Procyclidine } 10 \\
\text { Benztropine 4 } \\
\text { Procyclidine 5 } \\
\text { Ethopropazine } 100 \\
\text { Procyclidine 5 } \\
\text { Trihexyphenidyl 15 } \\
\text { \{rihexyphenidyl 6 } \\
\text { Amantadine 200 } \\
\text { None } \\
\text { Benztropine 2 } \\
\text { Benztropine 6 } \\
\text { \{ Benztropine 1 } \\
\text { Trihexyphenidyl 2 } \\
\text { Chlorophenoxamine } 150 \\
\text { Benztropine 3 } \\
\text { Trihexyphenidyl } 6 \\
\text { Amantadine 6 } \\
\text { Chlorophenoxamine } 150 \\
\text { Benztropine 2 } \\
\text { None } \\
\text { Ethopropazine 200 } \\
\text { Benztropine 2·5 } \\
\text { Amantadine 200 } \\
\text { Biperiden 10 } \\
\text { \{ Biperiden 20 } \\
\text { Amantadine 200 }\end{array}$ & $\begin{array}{l}\text { None } \\
\text { Same } \\
\text { Same } \\
\text { Same } \\
\text { Same } \\
\text { None } \\
\text { Same } \\
\text { Same } \\
\text { Same } \\
\text { Same } \\
\text { Same } \\
\text { Same } \\
\text { Same } \\
\text { Same } \\
\text { \{ Same } \\
\text { Same } \\
\text { None } \\
\text { Same } \\
\text { None } \\
\left\{\begin{array}{l}\text { Same } \\
\text { Same } \\
\text { None } \\
\text { None } \\
\text { None } \\
\text { Same } \\
\text { None } \\
\text { Same } \\
\text { None } \\
\text { Same } \\
\text { Benztropine 0.5 } \\
\text { None } \\
\text { Biperiden 10 } \\
\text { \{iperiden 10 } \\
\text { None }\end{array}\right.\end{array}$ & 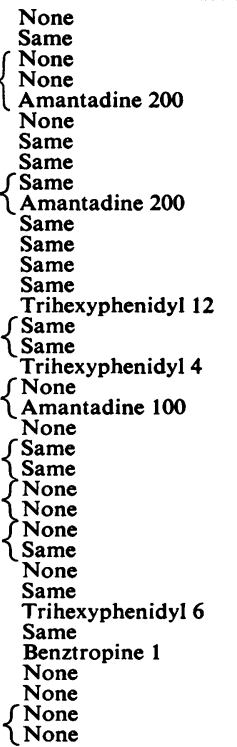 \\
\hline
\end{tabular}




\section{METHODS}

The patient group included 22 males and five females on levodopa therapy for Parkinson's disease between July 1969 and June 1970. They ranged in age from 44 to 71 years with a mean age of $58 \cdot 11$, and SD of \pm 6.65 years (Table 1). All patients obtained verbal intelligence scores in the average to superior range with a mean IQ of $111 \cdot 11$ (which places them at the 75th percentile of their age group) and an SD of 11.92. Educationally, they scored above average: mean years of education were 14.37 ; SD 3.96 . By the patients' own accounts, the onset of the disease began nine months to 34 years before levodopa therapy.

Eight patients had had cryothalamotomy performed: three on the left, three on the right, and two bilaterally. All cryothalamotomies had been performed 10 months to two years before psychological testing. Twenty-three of the 27 patients had been taking anticholinergic anti-Parkinsonism medications initially. In some cases, after approximately three months of levodopa, some of these anticholinergic medications were decreased in dosage or discontinued for a brief period of time (Table 2). After 15 months of levodopa therapy, the amount of anticholinergic medications in addition to levodopa was again approximately the same as the pretest level. The level of levodopa dosage was about the same after three months (ranging from 2 to $9 \mathrm{~g}$ with a mean of $4.44 \pm 1.55 \mathrm{~g}$ ) and 15 months (ranging from 2 to $7 \mathrm{~g}$ with a mean level of $4 \cdot 14 \pm 1 \cdot 30 \mathrm{~g}$ ).

The patients had general physical and neurological examinations at one to three month intervals throughout the study. On each patient the examinations were performed by the same neurologist. The patients' neurological state was graded in a number of ways (Treciokas et al., 1971; McDowell and Markham, 1971). One of these was the following overall assessment of the stages of Parkinson's disease: (1) unilateral involvement only; (2) bilateral involvement; (3) first evidence of impaired postural and righting reflexes by examination or by history of poor balance, falling, etc., disability mild to moderate; (4) fully developed severe disease, disability marked; (5) confinement to bed or wheelchair. A category (0) denoting no discernible motor involvement was added at the time of retest to describe the patients who had complete reversal of their motor symptoms.

CONTROL GROUP The controls were employees or volunteer workers at UCLA Hospital, physiotherapy patients without central nervous system disease, or relatives of the Parkinsonism patients. Thirteen males and 18 females comprised the control group and ranged in age from 42 to 71 years, mean age of 57.0 years, \pm 8.75 (Table 1 ). The two groups were comparable in age and verbal IQ. The patient group had completed more years of formal schooling than the control group and contained a larger proportion of males. The greater number of females in the control group may have biased this group toward elevated scores on emotional and physical symptoms, since women in our culture tend to admit more readily to physical and emotional symptoms than men.

PERSONALITY TEST The shortened version of the Minnesota Multiphasic Personality Inventory (MMPI) consisting of 447 statements relating to the individual's physical status, physical symptoms, morale, attitudes, and beliefs was selected as the test instrument (Dahlstrom and Welsh, 1960). The MMPI is a true-false personality questionnaire which offers objective test scores on characteristics associated with the individual's emotional functioning. The assumption underlying the test is that individuals similar to each other in important aspects of their personality and behaviour answer the questions in a similar manner.

The MMPI consists of three validity scales and 10 clinical scales. These scales were derived empirically (Dahlstrom and Welsh, 1960) on the basis of being able to differentiate specific patient groups from normal groups. Although the MMPI is interpreted by profile analysis (configuration of the elevated scales' scores) and not by a score on a single scale, a brief description of the individual scales is given below to acquaint the reader with the diversity of emotional pathology measured by the test. These scale descriptions are based on those of Dahlstrom and Welsh (1960) and Good and Brantner (1961).

In general, standard scores on all the scales in the range from 45-55 are within normal limits and indicate that the individual is able to function effectively emotionally and to respond to stress without crippling neurotic defenses or psychotic decompensation. As the standard scores increase and approach 70 and above, the individual is usually found to have an emotional disorder. The nature of the disorder is predicted by the profile or pattern of the elevated scores. Although a score of 65 and above is usually considered to be indicative of emotional symptomatology, the seriousness of an elevated score is determined not only by the height of the elevation but also by the nature of the scale. For example, a score of 65 on scale 5 (the scale measuring masculinity and femininity) for a college-educated male is a relatively benign finding, but a score of 65 on scale 6 (Paranoia scale) is suggestive of a moderate amount of suspiciousness, distrust, and possibly paranoid ideation.

The three validity scales ( $\mathrm{L}, \mathrm{F}$, and $\mathrm{K}$ ) assess the 


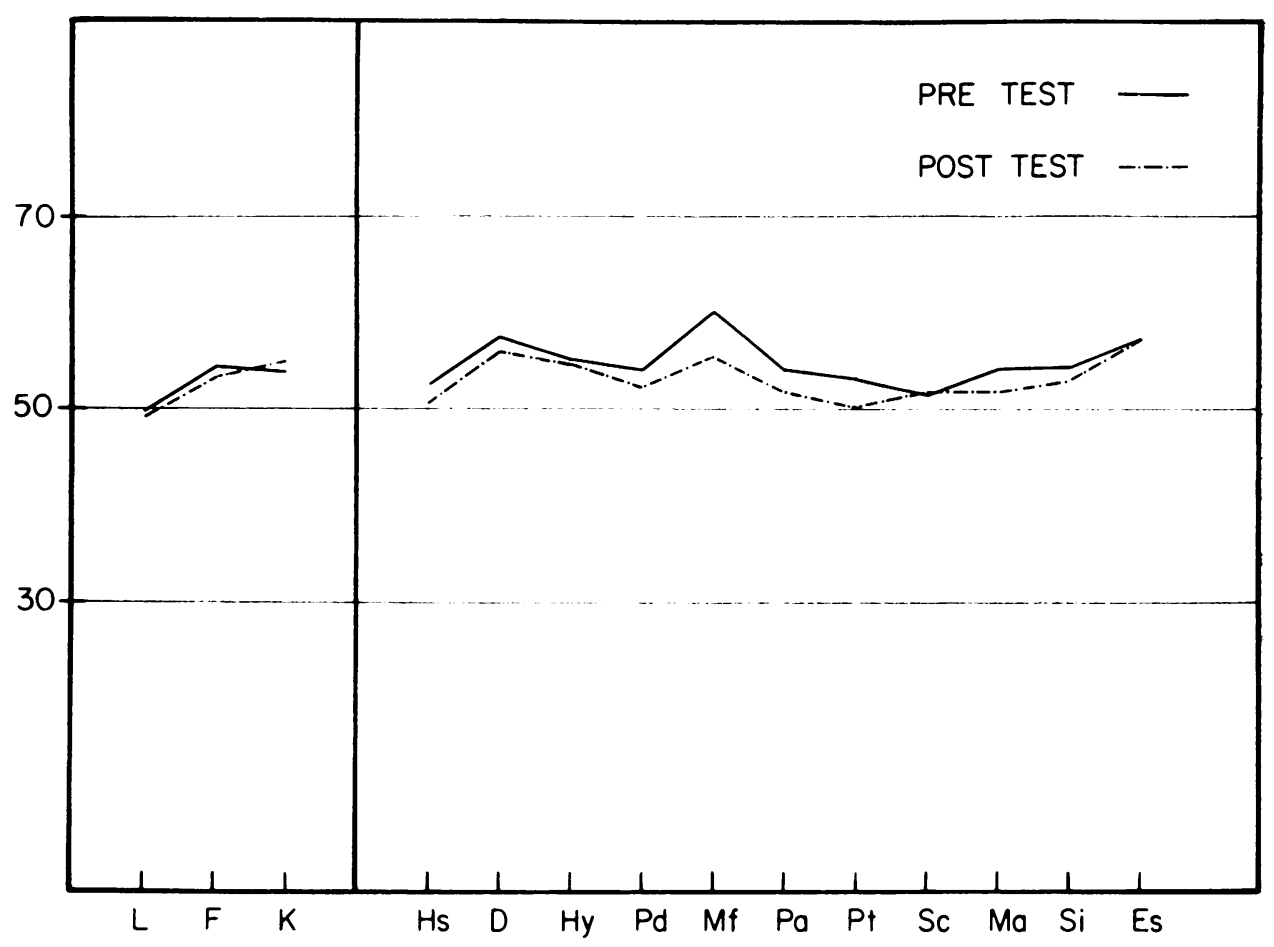

FIG. 1. Control subjects' mean MMPI scale scores (pre-test and three months post-test).

subject's test-taking attitudes and give information about the validity of his test. The Hypochondriasis or $\mathrm{Hy}$ scale indicates the presence of physical complaints and concern over physical health; the Depression or $\mathrm{D}$ scale (depression and general adjustment); the Hysteria or Hs scale (somatic complaints in response to stress and denial of personal difficulties); the psychopathic deviate or Pd scale (disregard of social customs and mores, emotional shallowness, impulsive actions, and difficulties with authority figures); the Masculinity-femininity or Mf scale (indicates masculine or feminine interest patterns); the Paranoia or $\mathrm{Pa}$ scale (heightened suspiciousness, ideas of reference, persecutory or grandiose self-concepts, and paranoid ideation); the Psychasthenia or Pt scale (anxiety, worry, fears, excessive vacillations in decision-making, concentration difficulties, and obsessive-compulsive tendencies); the Schizophrenia or Sc scale (bizarre and unusual thoughts or behaviour, and psychotic thinking); the Hypomania or Ma scale (emotional elation and/or instability, psychomotor excitement and flight of ideas); and Social IntroversionExtroversion or $\mathrm{Si}$ scale (social uneasiness and avoidance of other people); the Ego Strength or Es scale (good physical functioning, spontaneity, $\overrightarrow{\overrightarrow{3}}$ ability to share emotional experiences, good realitytesting, feeling of personal adequacy).

PROCEDURE The MMPI was answered by all patients (except two, see below) before beginning levodopa and after taking levodopa for approximately three months and again after approximately 15 months. These two patients answered the MMPI after being on $0.5 \mathrm{~g}$ levodopa per day for six and four days, respectively. There is little likehood that so brief a period of time on the medication could have influenced the patients' emotional or physical functioning. A control group of subjects answered the MMPI twice with a three month interval intervening between the two testings. The controls were not retested after 15 months.

\section{RESULTS}

Both the Parkinsonism and control groups' MMPI mean scores remained stable (Figs 1 and 2). Differences between test and retest scores for the two groups were analysed by $t$ tests for each group separately. 


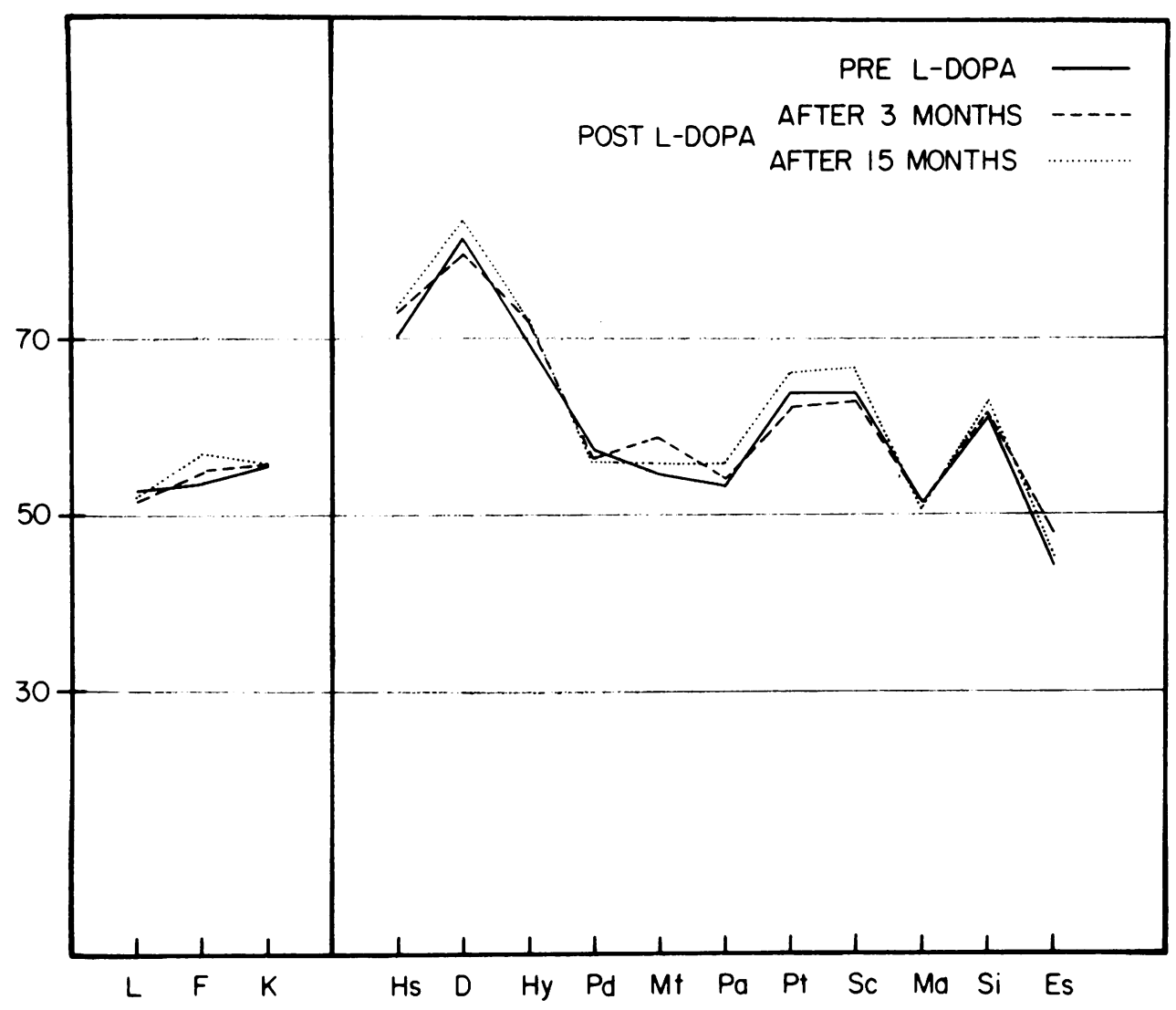

FIG. 2. Parkinsonism patients' mean MMPI scale scores (pre-L-dopa, three months, and 15 months post-L-dopa).

VALIDITY SCALE There were no significant differences between the two groups on the Validity Scales; scores are diagnostically within normal limits and indicate that the subjects' test results are valid. The control group's mean scores on all MMPI scales fell well within the normal range and did not change significantly on retest (Table 3 ). This test-retest stability suggests that any changes observed in the patients' group's scores reflect actual changes rather than testretest artefact.

RESULTS OF PATIENTS' SCALE SCORES AFTER THREE AND 15 MONTHS OF LEVODOPA None of the patients' 14 scale scores changed significantly from pretest to three-month or 15-month posttest (Table 4) even though the patients demon-
TABLE 3

CONTROL SUBJECTS' MMPI SCALES MEAN SCORES

\begin{tabular}{|c|c|c|c|c|c|}
\hline \multirow[b]{2}{*}{ Scale } & \multicolumn{2}{|c|}{ Mean $T$ scores } & \multirow[b]{2}{*}{$\begin{array}{c}t \\
\text { test }\end{array}$} & \multicolumn{2}{|c|}{$S D$} \\
\hline & $\begin{array}{c}\text { Initial } \\
\text { test }\end{array}$ & $\begin{array}{l}\text { After } \\
3 \mathrm{mth}\end{array}$ & & $\begin{array}{c}\text { Initial } \\
\text { test }\end{array}$ & $\begin{array}{l}\text { After } \\
3 \mathrm{mth}\end{array}$ \\
\hline $\mathbf{L}$ & $49 \cdot 7$ & $49 \cdot 1$ & 0.48 & $5 \cdot 8$ & $5 \cdot 2$ \\
\hline $\overrightarrow{\mathbf{F}}$ & $54 \cdot 3$ & $53 \cdot 1$ & 0.61 & $6 \cdot 8$ & $7 \cdot 9$ \\
\hline $\mathbf{K}$ & 53.9 & $54 \cdot 8$ & 0.42 & 8.7 & $9 \cdot 4$ \\
\hline Hs & $52 \cdot 5$ & $50 \cdot 5$ & 0.79 & 10.6 & $8 \cdot 5$ \\
\hline D & $57 \cdot 3$ & $55 \cdot 8$ & 0.54 & 10.9 & $11 \cdot 2$ \\
\hline Hy & 55.0 & $54 \cdot 5$ & 0.20 & $9 \cdot 1$ & 8.6 \\
\hline Pd & 53.9 & $52 \cdot 1$ & 0.81 & $9 \cdot 0$ & $9 \cdot 2$ \\
\hline Mf & $59 \cdot 6^{*}$ & $55 \cdot 4 *$ & 1.01 & $10 \cdot 4$ & 11.0 \\
\hline $\mathbf{P a}$ & 53.9 & $51 \cdot 8$ & 0.94 & $6 \cdot 8$ & $10 \cdot 0$ \\
\hline $\mathrm{Pt}$ & $52 \cdot 6$ & $50 \cdot 1$ & 1.02 & $10 \cdot 1$ & $9 \cdot 3$ \\
\hline Sc & $51 \cdot 3$ & 51.6 & 1.09 & $10 \cdot 2$ & $8 \cdot 6$ \\
\hline Ma & 54.0 & $51 \cdot 7$ & 0.93 & $9 \cdot 0$ & $9 \cdot 8$ \\
\hline $\mathrm{Si}$ & $54 \cdot 2$ & $52 \cdot 9$ & 0.55 & $8 \cdot 7$ & $9 \cdot 3$ \\
\hline Es & $57 \cdot 3$ & $57 \cdot 2$ & 0.04 & $10 \cdot 5$ & $10 \cdot 1$ \\
\hline
\end{tabular}

* Based on 13 control males. 
TABLE 4

PARKINSONISM PATIENTS' MEAN MMPI SCALES SCORES

\begin{tabular}{|c|c|c|c|c|c|c|c|c|}
\hline \multirow{2}{*}{$\begin{array}{c}\text { MMPI } \\
\text { scale }\end{array}$} & \multicolumn{2}{|c|}{ Mean $T$ scores } & \multirow{2}{*}{$\stackrel{t}{t}$} & \multicolumn{2}{|c|}{$S D$} & \multirow{2}{*}{$\frac{\text { Mean T score }}{\text { After }}$} & \multirow{2}{*}{$\begin{array}{c}t \\
t e s t\end{array}$} & \multirow{2}{*}{$\begin{array}{c}S D \\
\begin{array}{c}\text { After } \\
15 \mathrm{mth}\end{array}\end{array}$} \\
\hline & $\begin{array}{c}\text { Pre- } \\
\text { L-dopa }\end{array}$ & $\begin{array}{l}\text { After } \\
3 \mathrm{mth}\end{array}$ & & $\begin{array}{c}\text { Pre- } \\
\text { L-dopa }\end{array}$ & $\begin{array}{l}\text { After } \\
3 \text { mth }\end{array}$ & & & \\
\hline $\mathbf{L}$ & $52 \cdot 7$ & $51 \cdot 5$ & 0.74 & $6 \cdot 1$ & 6.0 & $52 \cdot 0$ & 0.39 & $6 \cdot 2$ \\
\hline $\mathbf{F}$ & $53 \cdot 7$ & $54 \cdot 8$ & 0.71 & 4.9 & $6 \cdot 1$ & $56 \cdot 7$ & $1 \cdot 71$ & 6.9 \\
\hline $\mathrm{K}$ & $55 \cdot 5$ & $55 \cdot 8$ & 0.11 & $8 \cdot 7$ & $10 \cdot 2$ & $55 \cdot 8$ & 0.12 & $9 \cdot 4$ \\
\hline Hs & $70 \cdot 2$ & $72 \cdot 9$ & 0.72 & $11 \cdot 8$ & $15 \cdot 5$ & $73 \cdot 7$ & $1 \cdot 21$ & $14 \cdot 2$ \\
\hline D & $81 \cdot 3$ & $79 \cdot 4$ & 0.50 & 14.4 & $14 \cdot 4$ & $83 \cdot 3$ & 0.46 & 16.6 \\
\hline $\mathrm{Hy}$ & $69 \cdot 7$ & $71 \cdot 7$ & 0.60 & $11 \cdot 2$ & $13 \cdot 2$ & $72 \cdot 1$ & 0.72 & $11 \cdot 7$ \\
\hline$P d$ & $57 \cdot 3$ & $56 \cdot 3$ & 0.37 & $9 \cdot 1$ & $10 \cdot 5$ & $55 \cdot 9$ & 0.45 & $13 \cdot 1$ \\
\hline Mf & $54 \cdot 5^{*}$ & $58 \cdot 6^{*}$ & 1.43 & $9 \cdot 4$ & $9 \cdot 5$ & $55 \cdot 6^{*}$ & $0 \cdot 70$ & $10 \cdot 8$ \\
\hline $\mathrm{Pa}$ & $53 \cdot 3$ & $54 \cdot 0$ & $0 \cdot 27$ & $9 \cdot 7$ & $9 \cdot 6$ & $55 \cdot 7$ & 0.91 & $9 \cdot 7$ \\
\hline $\mathrm{Pt}$ & $63 \cdot 7$ & $62 \cdot 1$ & 0.54 & $10 \cdot 2$ & $11 \cdot 7$ & 66.0 & 0.58 & 16.0 \\
\hline Sc & $63 \cdot 7$ & $62 \cdot 8$ & 0.32 & $9 \cdot 2$ & 10.7 & $66 \cdot 7$ & 1.00 & 13.4 \\
\hline $\mathbf{M a}$ & $51 \cdot 2$ & $51 \cdot 3$ & 0.02 & $9 \cdot 4$ & $9 \cdot 6$ & $50 \cdot 8$ & 0.19 & 7.9 \\
\hline $\mathrm{Si}$ & $61 \cdot 0$ & $61 \cdot 3$ & 0.12 & $9 \cdot 1$ & $8 \cdot 7$ & $62 \cdot 6$ & $0 \cdot 70$ & $8 \cdot 6$ \\
\hline
\end{tabular}

* Based on 22 males with Parkinsonism.

TABLE 5

PARKINSONISM AND CONTROL GROUPS' MEAN SCALES SCORES

\begin{tabular}{|c|c|c|c|c|c|c|}
\hline \multirow{2}{*}{$\begin{array}{c}\text { MMPI } \\
\text { scale }\end{array}$} & \multicolumn{2}{|c|}{ Initial mean scores } & \multirow{2}{*}{$\begin{array}{c}t \\
t e s t\end{array}$} & \multicolumn{2}{|c|}{ 3-month mean scores } & \multirow{2}{*}{$\begin{array}{c}t \\
t e s t\end{array}$} \\
\hline & Parkinsonism & Control & & Parkinsonism & Control & \\
\hline $\mathrm{L}$ & $52 \cdot 7$ & $49 \cdot 7$ & 1.91 & $51 \cdot 5$ & $49 \cdot 1$ & $1 \cdot 62$ \\
\hline$F$ & $53 \cdot 7$ & $54 \cdot 3$ & 0.39 & $54 \cdot 8$ & $53 \cdot 1$ & 0.92 \\
\hline $\mathrm{K}$ & $55 \cdot 5$ & 53.9 & 0.70 & $55 \cdot 8$ & $54 \cdot 8$ & 0.39 \\
\hline Hs & $70 \cdot 2$ & $52 \cdot 5$ & $5.98+$ & $72 \cdot 9$ & $50 \cdot 5$ & $6.68+$ \\
\hline D & $81 \cdot 3$ & $57 \cdot 3$ & $7.07 \dagger$ & $79 \cdot 4$ & $55 \cdot 8$ & $6.89 \dagger$ \\
\hline Hy & $69 \cdot 7$ & 55.0 & $5.43 \dagger$ & $71 \cdot 7$ & $54 \cdot 5$ & $5 \cdot 78+$ \\
\hline$P d$ & $57 \cdot 3$ & 53.9 & 1.43 & $56 \cdot 3$ & $52 \cdot 1$ & 1.61 \\
\hline $\mathrm{Pa}$ & $53 \cdot 3$ & $53 \cdot 9$ & $0 \cdot 27$ & $54 \cdot 0$ & $51 \cdot 8$ & 0.85 \\
\hline $\mathrm{Pt}$ & $63 \cdot 7$ & 52.6 & $4 \cdot 15 \dagger$ & $62 \cdot 1$ & $50 \cdot 1$ & $4 \cdot 28+$ \\
\hline Sc & $63 \cdot 7$ & $51 \cdot 3$ & $4 \cdot 87 \dagger$ & $62 \cdot 8$ & 51.6 & $4 \cdot 35+$ \\
\hline $\mathrm{Ma}$ & $51 \cdot 2$ & $54 \cdot 0$ & $1 \cdot 15$ & $51 \cdot 3$ & $51 \cdot 7$ & $0 \cdot 16$ \\
\hline $\mathrm{Si}$ & $61 \cdot 0$ & $54 \cdot 2$ & $2 \cdot 90^{*}$ & $61 \cdot 3$ & $52 \cdot 9$ & $3.55+$ \\
\hline Es & $44 \cdot 0$ & $57 \cdot \overline{3}$ & $5.01+$ & $47 \cdot 5$ & $57 \cdot 2$ & $3.93 \dagger$ \\
\hline
\end{tabular}

* $\mathrm{P}<0.01$.

$+\mathbf{P}<0.001$.

strated significant improvement in their motor function.

DIFFERENCES IN MMPI SCALE SCORES BETWEEN PATIENT AND CONTROL GROUP On initial testing and after three months, the patient group scored significantly higher than the control groups on seven of the 13 MMPI scales (Table 5), Hs, D, $\mathrm{Hy}, \mathrm{Pt}, \mathrm{Sc}, \mathrm{Si}$, and Es. On all these elevated scales, the scores are diagnostically as well as quantitatively significant in the range indicating mild to moderate emotional disturbance (Dahlstrom and Welsh, 1960; Good and
Brantner, 1961). The control group scored well within normal limits on all scales.

MMPI PROFILE INTERPRETATIONS The controlo group's MMPI profile is within normal limits. on all the subtest scores, indicating that the control subjects as a group had no serious neurotic or psychotic pathology that was? interfering with their daily living (Fig. 1).

In contrast, the patient group's elevated profile (Fig. 2) suggests considerable maladjustmento with complaints of physical illness, depression, $N$ and hopelessness which would appear to be to a N 
large extent a reality-based response to the progressively debilitating nature of Parkinson's disease. The patient group's post-test MMPI profiles do not deviate enough from their pretest MMPI profile to justify separate interpretations. The following description therefore is characteristic of the profiles. Elevated profiles of this type have been associated with personality traits of tension, worrying, a pessimistic outlook, thoughts about death and suicide, loss of efficiency, feelings of apathy, inadequacy, selfdoubt, marked self-depreciation, health worries, and loss of initiative.

The Depression scale remained unchanged in
TABLE 6

PARKINSONISM PATIENTS' MEAN SCORES ON DISABILITY RATINGS

\begin{tabular}{cccc}
\hline $\begin{array}{c}\text { Stages of } \\
\text { Parkinson's disease }\end{array}$ & Pre-L-dopa & After 3 mth & After 15 mth $^{*}$ \\
\hline 0 & 0 & 5 & 6 \\
1 & 5 & 15 & 15 \\
2 & 13 & 5 & 3 \\
3 & 7 & 2 & 2 \\
4 & 2 & 0 & 0 \\
5 & 0 & 0 & 0 \\
Mean & 2.22 & $1 \cdot 15$ & 1.04 \\
SD & 0.85 & 0.82 & 0.82 \\
\hline
\end{tabular}

* One patient had not been evaluated clinically after 15 months of levodopa treatment.

TABLE 7

a. FREQUENCY OF MMPI PROFILE TYPES IN PARKINSONISM AND CONTROL GROUPS

\begin{tabular}{|c|c|c|c|c|c|}
\hline \multirow[t]{2}{*}{ Profile type } & \multicolumn{3}{|c|}{ Parkinsonism patients } & \multicolumn{2}{|c|}{ Controls } \\
\hline & Pre-levodopa & $3 m t h$ & $15 \mathrm{mth}$ & Pre-test & $3 m t h$ \\
\hline $\begin{array}{l}\text { 3. Abnormal depressed } \\
\text { 4. Abnormal nondepressed }\end{array}$ & $\begin{array}{c}10 \\
7\end{array}$ & $\begin{array}{c}10 \\
9\end{array}$ & $\begin{array}{c}12 \\
9\end{array}$ & 2 & 1 \\
\hline $\begin{array}{l}1 \text { and } 2 \text { ((Normal) } \\
3 \text { and } 4 \text { (Abnormal) }\end{array}$ & $\begin{array}{l}10 \\
17\end{array}$ & $\begin{array}{r}8 \\
19\end{array}$ & $\begin{array}{r}6 \\
21\end{array}$ & $\begin{array}{r}28 \\
3\end{array}$ & $\begin{array}{r}29 \\
2\end{array}$ \\
\hline
\end{tabular}

spite of the fact that the patients showed much improvement in their physical state. This improvement is shown in the shift of all patients to a less severe stage of Parkinson's disease (Table 6). The pre-levodopa mean stage of Parkinson's disease was $2 \cdot 22$; after three months, the mean rating was $1.15(\mathrm{P}<0.01)$; after 15 months of levodopa therapy, the mean stage was $1.04(\mathrm{P}<0.01)$. There was no significant difference between the patients' improvement in motor ability after three and 15 months of levodopa therapy $(t=0.49 ; 0.6<\mathrm{P}<0.7)$.

ADDITIONAL ANALYSIS OF PATIENTS' DEPRESSION SCALE Changes in patients' Depression subgroup categories after three and 15 months Because the Parkinsonism patients' highest score occurred on the Depression scale, a more detailed analysis of this scale is included below. Although the patients as a group did not significantly change their mean Depression scale score over the 15 months of levodopa therapy, it is possible that a subgroup significantly changed their individual Depression scores. Another method of analysing the MMPI profiles is to categorize them individually into diagnostic subgroups measuring the degree of depression and/ or emotional abnormality present in each patient. Gilberstadt and Farkas (1961) developed this method of analysing MMPI profiles which offers more detailed analysis of each patient's MMPI pattern than do group mean score

TABLE 8

PARKINSONISM PATIENTS' AND CONTROLS' INDEX OF PSYCHOPATHOLOGY (IP) MEAN SCORES

\begin{tabular}{lccccc}
\hline & \multicolumn{2}{c}{ Parkinsonism } & & \multicolumn{2}{c}{ Controls } \\
\cline { 2 - 3 } \cline { 5 - 6 } & Mean & $S D$ & & Mean & $S D$ \\
\hline Pre-levodopa & 2.89 & 1.22 & & 2.13 & 1.26 \\
After 3 mth & 2.96 & 1.40 & & 2.03 & 1.35 \\
After 15 mth & 3.37 & 1.57 & & - & - \\
\hline
\end{tabular}


comparisons. Their method involves examining the configuration of the scales' scores and categorizing each individual MMPI profile into one of the four following categories: (1) an MMPI profile with not more than 1 scale over $70, \mathrm{D}$ greater than 60 is categorized as normal depressed; (2) an MMPI profile with not more than 1 scale over 70 , and D less than 60 is a normal nondepressed one; (3) an MMPI profile with 2 or more scales over 70 , and D greater than 80 is an abnormal depressed one; (4) an MMPI profile with 2 or more scales over 70 , and D less than 80 is an abnormal nondepressed one. This method which places emphasis on one's score on the $\mathbf{D}$ scale is particularly relevant in examining the MMPI profiles of the Parkinsonism patients, since their Depression scale score was their highest mean score. Table $7 \mathrm{a}$ gives the distribution of Parkinsonism patients and normal controls on these four MMPI categories.

EFFECTS OF LEVODOPA ON THE PARKINSONISM PATIENTS' GILBERSTADT-FARCAS' CATEGORIES Although more Parkinsonism patients were categorized as abnormal depressed and abnormal nondepressed after being on levodopa, the increase was not statistically significant $;^{2}$ after three months, $\chi^{2}=2 \cdot 17, \quad \mathrm{P}<0.50 ;$ after 15 months, $\chi^{2}=3 \cdot 52, \mathrm{P}<0 \cdot 30$ ).

COMPARING PATIENTS' AND NORMALS' GILBERSTADT-FARKAS' SUBGROUPS In categorizing the MMPI test profiles into the four categories denoting normal and abnormal depressed and nondepressed subjects, the distributions of the two groups were found to be reliably different both for pretest $\left(\chi^{2}=29.87, \mathrm{P}<0.001\right)$ and for three month post-test $\left(\chi^{2}=31.03, P<0.001\right)$. On inspecting Table $7 \mathrm{a}$, it is apparent that more Parkinsonism patients were classified in the abnormal depressed and abnormal nondepressed categories than were the controls. To illustrate more clearly the significant difference between the Parkinsonism and control subjects' MMPI classification, the four Gilberstadt and Farkas' categories were recombined into two categories: normal (combining categories 1 and 2) and abnormal (combining categories 3 and 4).

2 G-test was the statistical test used in analysis of these data (Sokal \& Rohlf, 1969).
Table $7 \mathrm{~b}$ compares the Parkinsonism and control groups on the number of normal and abnormal profiles. The Parkinsonism patients obtained more abnormal profiles than the controls at pretest $\left(\chi^{2}=21 \cdot 85, \mathrm{P}<0.001\right)$ and at three month post-test $\left(\chi^{2}=31.61, \mathrm{P}<0.001\right)$.

LEVODOPA'S INFLUENCE ON DEGREE OF PSYCHOPATHOLOGY The Index of Psychopathology (Ip) $\stackrel{\vec{P}}{\stackrel{9}{9}}$ score was calculated for each Parkinsonism patient in order to obtain an objective measure $\frac{\bar{\sigma}}{\bar{\omega}}$ of the amount of psychopathology in each $\overrightarrow{\widetilde{\sigma}}$ patient's pre-levodopa, three-month levodopa, $\stackrel{\circ}{0}$ and 15-month levodopa MMPIs. The Ip score ${ }^{\circ}$ was developed by Sines and Silver (1963) and $\vec{\circ}$ Meier and French (1965) in an attempt to $\overrightarrow{\vec{\omega}}$ quantify the concept of degree of psycho- $\omega$ pathology as reflected in the MMPI $\mathrm{Pa}$ (Paranoia) and Sc (Schizophrenia) scale score? elevations and is based on the following regression equations:

$$
\begin{aligned}
& \text { Ip }=0 \cdot 10 \mathrm{~Pa}+0 \cdot 06 \mathrm{Sc}-6.26 \text { (males) } \\
& \text { Ip }=0.08 \mathrm{~Pa}+0 \cdot 10 \mathrm{Sc}-7 \cdot 36 \text { (females) }
\end{aligned}
$$

An individual with a high Ip score is one wh has endorsed many items on these scales indica ing oversensitivity, suspiciousness, ideas of $\stackrel{\mathbb{D}}{\exists}$ reference and persecution, bizarre and unusua 1 thoughts and behaviour.

INFLUENCE OF LEVODOPA ON PARKINSONISM PATIENTS' IP MEAN SCORES The patients' mean Ip score did not increase significantly after being on levodopa for three months (Table 8), $t=0 \cdot 28$, $\mathbf{P}<0.50$, after 15 months of levodopa treatment, $\stackrel{\mathbb{Q}}{\Omega}$ however, the Ip score increased significantly $\overrightarrow{\vec{F}}$ (Table 8) indicating an increase in the amount of 3 psychopathology after 15 months of levodopa,, $t=1.83, \mathrm{P}=0.05$. The increase in the Psycho-0. pathology Index score occurred after the patients had been on levodopa over three months, sinceo there is a significant increase in Ip score from the three month to 15 month interval.

COMPARISON BETWEEN PARKINSONISM PATIENTS AND CONTROLS' PSYCHOPATHOLOGY INDEX SCORES The patients obtained significantly higher Ipo mean scores than the normals at the time of the initial test, $t=2.33 ; \mathrm{P}=0.01$; and after the patients had been taking levodopa for three 0 months, $t=2 \cdot 57, \mathrm{P}<0.01$ (Table 8). 


\section{DISCUSSION}

One of the noteworthy findings in the study is the presence of moderate depression in Parkinsonism patients before levodopa therapy that is apparently resistant to the influence of improved motor functioning after three or 15 months of levodopa treatment. The patient's Depression scale score did not change significantly, even though clinically they had improved in motor ability. These data do not lend support to the observation (Yahr et al., 1969) that depression is alleviated by levodopa in many Parkinsonism patients. These authors observed their patients over a one year interval. In the present study, retesting occurred after three and 15 months of levodopa therapy. The discrepancy between the present findings of moderate depression in Parkinsonism patients before levodopa therapy as well as afterward and Cherington's clinical observation (1970) that levodopa produces depression in some Parkinsonism patients indicates the need for further research in this area. The research should include a more thorough evaluation and more details about the patient's history in relation to his past emotional functioning.

Although the patients in the present study did not increase their Depression score significantly, the findings do not rule out the possibility that levodopa may exacerbate a pre-existing depressive reaction in individual patients with a psychiatric history of depressive reactions. There were no detailed psychiatric histories taken of the patients in the present study.

The finding that Parkinsonism patients remain moderately depressed in spite of significant improvement in their motor functioning after levodopa treatment suggests that the depression is probably not a reactive one related to impaired physical functioning.

That the Parkinsonism patients' mean Psychopathology Index (Ip) score increased significantly after 15 months of levodopa treatment lends support to the clinical observations of Sacks et al. (1970), Tobias and Merlis (1970), and Damasio et al. $(1970,1971)$ that levodopa exacerbates psychotic symptoms in demented and schizophrenic patients and in patients with a previous psychiatric history. The present study's patient group was relatively intact emotionally before levodopa therapy and the increase in their psychopathology score appears to reflect the emergence of some borderline psychotic thinking, but no actual psychosis.

The one Parkinsonism patient excluded from the present study who resembled the demented patients of Sacks and his associates did not complete his MMPI test. Although he scored in the average range on his verbal intelligence test, his daily behaviour suggested the confusion and memory loss that is associated with organic brain syndrome. It is unfortunate that there were no MMPI test scores on this patient.

Observations by Duvoisin and Katz (1968) assign a prominent role to the anticholinergic drugs in the emergence of psychiatric symtoms in some patients. They have described typical symptoms arising from the anticholinergic syndrome that are very similar to those ascribed to levodopa, such as confusion, agitation, hallucinations, stupor, delirium, and psychotic thinking. Duvoisin and Katz have reported that anticholinergic intoxication occurs with appreciable frequency in patients with extrapyramidal disease who are being treated with any of the standard anticholinergic medications and responds readily to physostigmine therapy.

In the present study, patients were maintained on relatively mild dosages of anticholinergic medications which probably did not interfere with their emotional functioning. Because anticholinergic medications are often prescribed in conjunction with levodopa, further research on patients being maintained on higher dosages of anticholinergic medications may help resolve some of the conflicting reports of levodopa effects on emotional disturbances in Parkinsonism patients.

The Parkinsonism patients scored highest on scales D (Depression), Hs (Hypochondriasis), and $\mathrm{Hy}$ (Hysteria). These three scales have frequently been found elevated in the test profiles of neurological patients and have been interpreted as reflecting a depressive reaction in patients with physical symptoms of a chronic nature. However, in interpreting the present MMPI profiles of the patients with Parkinson's disease, it is not possible to delineate the aetiology of the patients' depression from psychological test results. The depression may be reactive in nature or endogenous in the sense of having an organic 
basis, or a combination of a reactive-endogenous depression.

The patients' moderately to severely elevated scores on these scales suggest a pervasive maladjustment with a preoccupation with physical functioning and feelings of hopelessness. Sadness, moodiness, irritability, tension, worry, and pessimism are all indicated. Indecision and inability to get started are to be expected. The patients' self-esteem and self-initiative appear to have been undermined and replaced by feelings of inadequacy and self-doubt. Socially introverted behaviour and social withdrawal are also indicated and suggest an inability to feel comfortable in the presence of other people. The patients' reality-testing appears to be fairly intact and indicates they are aware of their impaired functioning.

The MMPI profile interpretation corroborates much of the clinical description of emotional symptoms found in patients with Parkinson's disease mentioned in the above research, especially that of Jackson et al. (1923). The objective data from the MMPI test results lend support to Jackson and his associates' contention that emotional symptomatology is a frequent symptom of Parkinson's disease.

Drugs used in the study were Akineton biperiden), Artane (trihexyphenidyl $\mathrm{HCl}$ ), Cogentin (benztropine mesylate MSD), Kemadrin (pro-cyclidine hydrochloride), Parsidol (ethopropazine), Phenoxene (chlorophenoxamine), and Symmetrel (amantadine HCl).

We are indebted to Dr. Alexander Caldwell, Assistant Clinical Professor, Department of Psychiatry, Neuropsychiatric Institute, UCLA, for his valuable suggestions and advice on the MMPI interpretations. Mrs. F. C. Wang was of great service to the study in constructing the Figures and with the statistical analyses of the data.

\section{REFERENCES}

Barbeau, A. (1969). L-dopa therapy in Parkinson's disease: a critical review of nine years' experience. Canadian Medical Association Journal, 101, 791-800.

Calne, D. B., Stern, G. M., Laurence, D. R., Sharkey, J., and Armitage, P. (1969). L-dopa in postencephalitic parkinsonism. Lancet, 1, 744-747.
Cherington, M. (1970). Parkinsonism, L-dopa and mental depression. Journal of the American Geriatrics Society, 18, 513-516.

Cotzias, G. C., Papavasiliou, P. S., and Gellene, R. (1969). Modification of Parkinsonism-chronic treatment with Ldopa. New England Journal of Medicine, 280, 337-345.

Dahlstrom, W. G., and Welsh, G. S. (1960). The MMPI Handbook: A Guide to Use in Clinical Practice and Research. University of Minnesota Press: Minneapolis.

Damasio, A. R., Lobo-Antunes, J., and Macedo, C. (1971). Psychiatric aspect in Parkinsonism treated with L-dopa. Journal of Neurology, Neurosurgery, and Psychiatry, 34, 502-507.

Damásio, A. R., Lobo-Antunes, J., and Macedo, C. (1970). L-dopa, parkinsonism, and depression. Lancet, 2, 611-612.

Duvoisin, R. C., and Katz, R. (1968). Reversal of central anticholinergic syndrome in man by physostigmine. Journal of the American Medical Association, 206, 1963-1965.

Gilberstadt, H., and Farkas, E. (1961). Another look at MMPI profile types in multiple sclerosis. Journal of Consulting Psychology, 25, 440-444.

Good, P. and Brantner, J. P. (1961). The Physician's Guide to the MMPI. University of Minnesota Press: Minneapolis.

Jackson, J. A., Free, G. B. M., and Pike, H. V. (1923). The psychic manifestations in paralysis agitans. Archives of Neurology and Psychiatry, 10, 680-684.

Jenkins, R. B., and Groh, R. H. (1970a). Psychic effects in $\square$ patients treated with levodopa. Journal of the American Medical Association, 212, 2265.

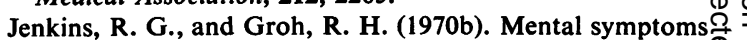

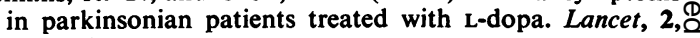
177-180.

Klawans, H. L., Jr., and Garvin, J. S. (1969). Treatment of parkinsonism with L-dopa. Diseases of the Nervous System, 30, 737-746.

McDowell, F., Lee, J. E., Swift, T., Sweet, R. D., Ogsbury, J. S., and Kessler, J. T. (1970). Treatment of Parkinson's syndrome with $\mathbf{L}$ dihydroxyphenylalanine (levodopa). Annals of Internal Medicine, 72, 29-35.

McDowell, F. H., and Markham, C. H. (Eds.) (1971). Recent Advances in Parkinson's Disease. Davis: Philadelphia.

Marsh, G. G., Markham, C. M., and Ansel, R. (1971). Levodopa's awakening effect on patients with Parkinsonism. Journal of Neurology, Neurosurgery, and Psychiatry, 34, 209-218.

Mawdsley, C. (1970). Treatment of Parkinsonism with laevo-dopa, British Medical Journal, 1, 331-337.

Meier, M. J., and French, L. A. (1965). Changes in MMPI scale scores and an index of psychopathology following unilateral temporal lobectomy for epilepsy, Epilepsia, 6, 263-273.

Mindham, R. H. S. (1970). Psychiatric symptoms in Parkinsonism. Journal of Neurology, Neurosurgery and Psychiatry, 33, 188-191.

Mjönes, H. (1949). Paralysis agitans. A clinical and genetic study. Acta Psychiatrica et Neurologica, Supplement, 54.

Patrick, H. T., and Levy, D. M. (1922). Parkinson's disease. A clinical study of one hundred and forty-six cases. Archives of Neurology and Psychiatry, 7, 711-720.

Sacks, O. W., Messeloff, C., Schartz, W., Goldfarb, A., and Kohl, M. (1970). Effects of L-dopa in patients with dementia. Lancet, 1, 1231.

Satz, P., and Mogel, S. (1962). An abbreviation of the WAIS for clinical use. Journal of Clinical Psychology, 18, 77-80.

Schwab, R. S., and England, A. C. (1958). Parkinson's disease. Journal of Chronic Disease, 8, 488-509. 
Sines, L. K., and Silver, R. J. (1963). An index of psychopathology (Ip) derived from clinicians' judgments of MMPI profiles. Journal of Clinical Psychology, 19, 324-326.

Sokal, R. R., and Rohlf, F. J. (1969). Biometry: The Principles and Practice of Statistics in Biological Research, p. 599. Freeman: San Francisco.

Tobias, J. A. Y., and Merlis, S. (1970). Levodopa and schizophrenia. Journal of the American Medical Association, 211, 1857.

Treciokas, L. J., Ansel, R. D., and Markham, C. H. (1971). One to two year treatment of Parkinson's disease with levodopa. California Medicine, 114, No. 5, 7-14.
Wagshul, A. M., and Daroff, R. B. (1969). Depression during L-dopa treatment. Lancet, 2, 592.

Warburton, J. W. (1967). Depressive symptoms in Parkinson patients referred for thalamotomy. Journal of Neurology, Neurosurgery, and Psychiatry, 30, 368-370.

Yahr, M. D., Duvoisin, R. C., Hoehn, M. M., Schear, M. J., and Barrett, R. E. (1968). L-Dopa (L,3,4-dihydroxyphenylalanine)-its clinical effects in parkinsonism. Transactions of the American Neurological Association, 93, 56-63.

Yahr, M. D., Duvoisin, R. C., Schear, M. J., Barrett, R. E., and Hoehn, M. M. (1969). Treatment of parkinsonism with levodopa. Archives of Neurology, 21, 343-354. 